\title{
Numerical and experimental assessment of railway-induced ground vibrations generated by IC/IR trains in Brussels
}

\author{
Georges Kouroussis $^{\mathrm{a}}$ and Olivier Verlinden ${ }^{\mathrm{b}}$ \\ University of Mons, Department of Theoretical Mechanics, Dynamics and Vibrations, 31 Boulevard Dolez, 7000 Mons, \\ Belgium
}

\begin{abstract}
Nowadays, the rising demand for new railway networks in Brussels is associated to discomfort and disturbance felt by the neighbourhood. This problem is a major concern of inhabitant surrounding rail infrastructure and causes part of the delay in the Brussels RER network construction. The present paper focuses on the vibratory nuisances generated by domestic trains in Brussels region. A compound experimental/numerical analysis is presented, based on recent investigations on line L161 between Brussels and Luxembourg. A specific site was chosen due to the presence of a singular rail surface defect which induces large ground vibrations when trains pass over. The effect of this defect is examined by means of free field ground vibrations measured during the passing of an AM96 unit, and completed by numerical results obtained from a numerical model. For this assessment, a fully 3D numerical prediction model is built, based on a two-step approach which combines multibody analysis of the vehicle and finite element analysis of the track and surrounding ground. Calculated high ground vibrations stem from singular rail surface defects. The prediction model is validated first and then used to quantify the gain brought by fixing of rail surfaces, with a reduction of local defects.
\end{abstract}

\section{Introduction}

Problems of railway-induced ground vibrations received considerable attention these last years. Due to the development of new networks, complains are more and more important to such an extent to hinder the prosperity of new solution to traffic congestion. Among these complaints, vibrations take an important place since they generate annoyance for humans and possible damage to buildings. Scientifically speaking, the mastering of ground vibration sources and their effects on neighbour structures is not sufficiently known due to the difficulty to model all the components that intervene in the generation and the propagation of ground waves [1]. A recent example coming from Brussels can be pointed out. The new RER network (réseau express régional, i.e. regional express network) has been planned for a long time. The first draft of the network was published in 1995 but administrative complexity and dweller complaints delayed the service, which is now expected for 2019. However, several additonal delays were recently announced and some infrastructures could not be placed in service before 2025 !

Various experimental studies were performed in existing European high-speed railway lines in order to assess the possible parameters influencing high-vibrations levels [2-7] but these findings cannot be transposed to domestic lines. Figure 1 dissects the problem in terms of the vehicle speed. The high-speed phenomenon is the most studied case in scientific literature. The main contribution on ground vibration is the quasi-static loading

\footnotetext{
a e-mail: georges . kouroussis@umons . ac . be

b e-mail: olivier.verlinden@umons.ac.be
}

produced by the fast passing of the vehicle. The track quality does not play an important role because railway operators attach importance to the quality of the rail profile, regularly improved with grinding machines. This is not the case in low-speed urban network where a lot of local defects abound the rail rolling surfaces: this main excitation is produced by practical rail discontinuities like crossing, switch gears, and rail joints. The quasistatic loading has a small effect of the produced ground vibrations [8]. Between these two extremes, domestic intercity trains travelling at moderate speeds present excitation mechanisms that are a combination of those experienced on both high speed and urban railway lines. Quasi-static track deflection has a non-negligible influence on ground vibrations, in addition to its already singular defects effects.

As the sources of vibration begin in the wheel/rail contact, it is not pointless to study the vehicle dynamics interaction with the track and the soil. In a general way, Auersch and Said [10] demonstrated, by comparing several excitation sources (road and rail traffic, vibratory construction work, explosions,...), that the attenuation of ground vibrations with increasing distance $d$ strongly depends on the source. Costa et al. [11] have shown the importance of integrating a multibody model of the vehicle in the track/soil simulation and they have shown that the sprung masses have non significant effects on the ground vibration motion. Kouroussis et al. [8] have also analysed the vehicle contribution in the case of an important local defect: without introducing countermeasures in the track or in the soil, it is possible to reduce the energy transmitted from the track to the ground (up to $70 \%$ ) by modifying the mechanical characteristics of the train. But the same 


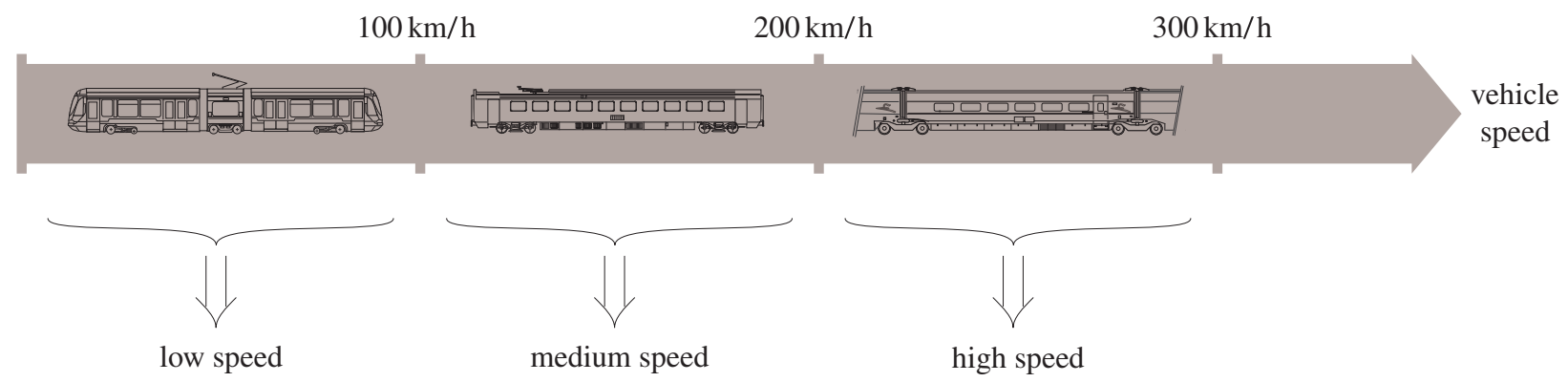

- Track deflection negligible

- Presence of local defects

- Very good quality of the track

- Track deflection (transient loading)

Figure 1. Synopsis of parameters influencing railway-induced ground vibrations [9].

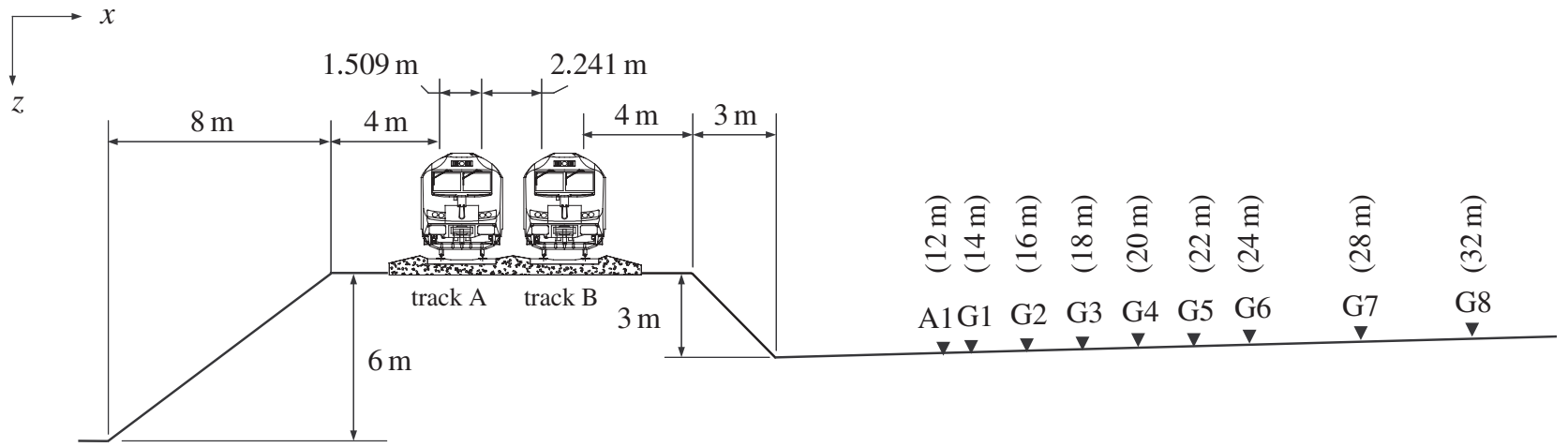

Figure 2. Investigated site and location of measurement points.

effect has not thoroughly been observed in the case of a distributed overall roughness, except a recent study [12] brought by Kouroussis et al. without considering the entire vehicle configuration.

Field trials are typically retained for vibration assessment and are used to quantify antivibration solutions or to understand the effect of track or soil geometry. Connolly et al. [13] investigated the role of embankments on ground borne vibration levels at various distances from the track. Vogiatzis $[14,15]$ successfully validated the necessary mitigation measures for the protection of the Hellenic cultural heritage in Athens in the case of metro lines extensions. Nevertheless, experiments often show limitations if the railway line does not exist yet or if multiple sources of vibration are recorded (e.g. the track near a high-speed road). In that case, numerical models abound in literature and can be used instead of experimental investigations. For example, Laghrouche and Le Houédec [16] employed a two-dimensional model to analyse various shapes of wave barriers in achieving the desired level of ground vibration reduction. The choice of modelling assumptions is also of great importance.

In the related study, Kouroussis et al. [17] analysed three sites located along line L161 (between Watermael and Ottignies cities) in order to determine the track and soil characteristics. Several train passages were also recorded in order to quantify the horizontal and vertical ground vibrations induced by domestic trains. The L161 line will be included in the RER network and is scheduled to be expanded with two supplementary tracks. The present paper aims to be complementary to this aforementioned research by analysing the effect of rail surface conditions on the ground vibrations. One site is selected and one train type is analysed in seek of simplicity. The purpose of this work is also to complete the experimental data by results of sufficient interest obtained from a recent prediction model based on a finite element approach and suitable for complex geometries $[18,19]$. Emphasis is put on the specificities of the studied site: a singular rail surface defect and local embankment conditions. In addition to these conditions, the horizontal vibrations and vehicle speed are also discussed.

\section{Characteristics of the studied site}

Figure 2 shows the studied site, its geometry, and the location of sensors placed near the railway track during the experiments. The closest track to the sensor is denoted "track B" ("track A" is the farthest track). Vertical vibration levels were measured using $4.5 \mathrm{~Hz}$ geophones (mounted on $100 \mathrm{~mm}$ spikes) placed at distances between $14 \mathrm{~m}$ and $32 \mathrm{~m}$ from the track (the origin is the external side of track B). A seismic accelerometer were also placed at $12 \mathrm{~m}$ using a $300 \mathrm{~mm}$ spike. Several train types were recorded on this line but the present work focuses exclusively on the AM96 car. This unit is largely used by the Belgian railway operator SNCB for long-distance trains as it is one of the most recent makes in the carriage stock. Its excellent passenger comfort is due to the latest bogie technology for smoother rides up to $160 \mathrm{~km} / \mathrm{h}$ which is 
HVBX

HVB

HVADX

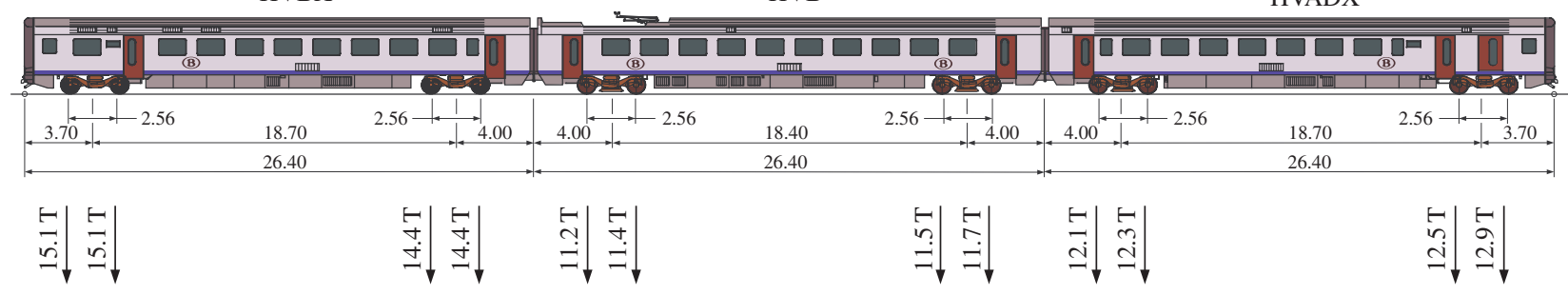

Figure 3. Configuration of the AM96 electric multiple unit.

copied over the high speed sector. Figure 3 presents the AM96 configuration and its main dimensions.

The studied site has the particularity of the presence of a singular surface defect on both rails of the track. With age, the two adjacent rails crushed the insulating material joining them and joint shape looks like a rectangular shape with height $\Delta h$ of $1 \mathrm{~mm}$ and length of $6 \mathrm{~mm}$.

Track in situ tests were performed in order to obtain the track dynamic parameters (railpad and ballast viscoelastic behaviour). Results are presented in [17]. Regarding the soil configuration (geometry and mechanical behaviour of each layer), seismic refraction method was used in evaluating the ground stiffness for geotechnical engineering purposes. Seismic refraction is based on primary body waves generated from impacts generated by sledge hammer. It analyses the primary wave velocities $c_{P, i}$ of each layer $i$ and the local geometry (depth and slope) of each refractor (between layers $i$ and $i+1$ ). To perform a refraction survey, the arrival times are recorded from receivers at the source and at several distances from the source. Knowing the receiver distances, the faster wave velocities and the layers depth are derived [20]. The obtained information is completed by geotechnical data provided by the railway operator in order to deduce the shear wave velocity $c_{S, i}$ and the density $\rho_{i}$ of each layer $i$. Final information is provided in one-dimensional format as a function of the depth (Fig. 4). It gives an accurate representation of the soil configuration by defining several layers of constant dynamic parameters. The soil material damping is estimated by fitting a ABAQUS finite element model of the soil with experimental results based on these field impact at soil surface. It is found that a viscous damping $\beta=0.0004 \mathrm{~s}$ is suitable for each soil layer [17].

\section{Detailed vibration prediction model development}

The proposed prediction model is based on two successive calculations. Complexity required the problem to be split. This approach allows using the most well-suited modelling approach for each subsystem. First of all, the dynamics of the vehicle/track subsystem is simulated by considering a multibody vehicle model moving on a flexible track with a track irregularity (Fig. 5). The wheel/rail forces are defined using Hertz's theory and allows coupling between the vehicle model and the track. The latter is defined as a flexible beam discretely supported by sleepers, including viscoelastic elements for the ballast and the railpads. To

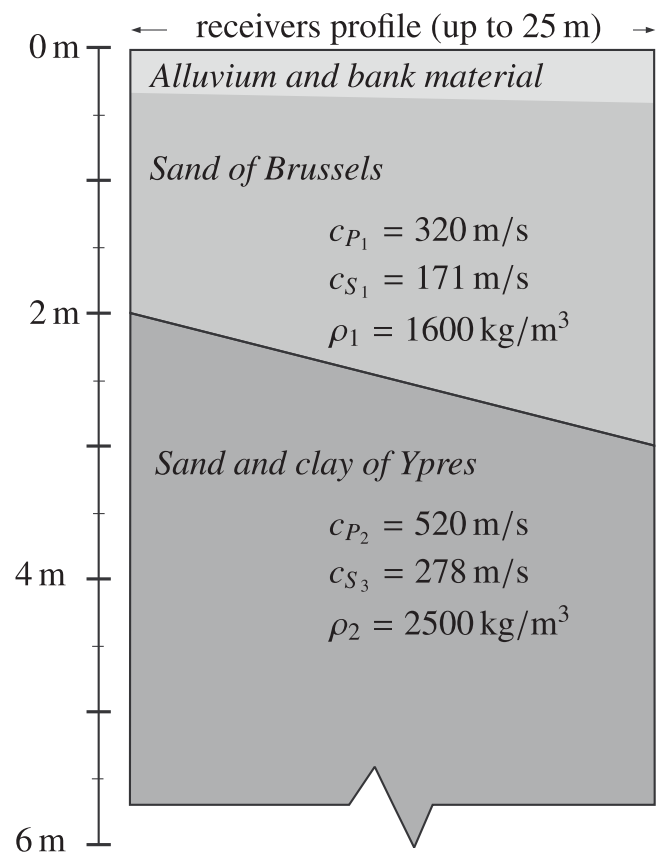

Figure 4. Stiffness map of the selected site based on collected data and seismic refraction survey.

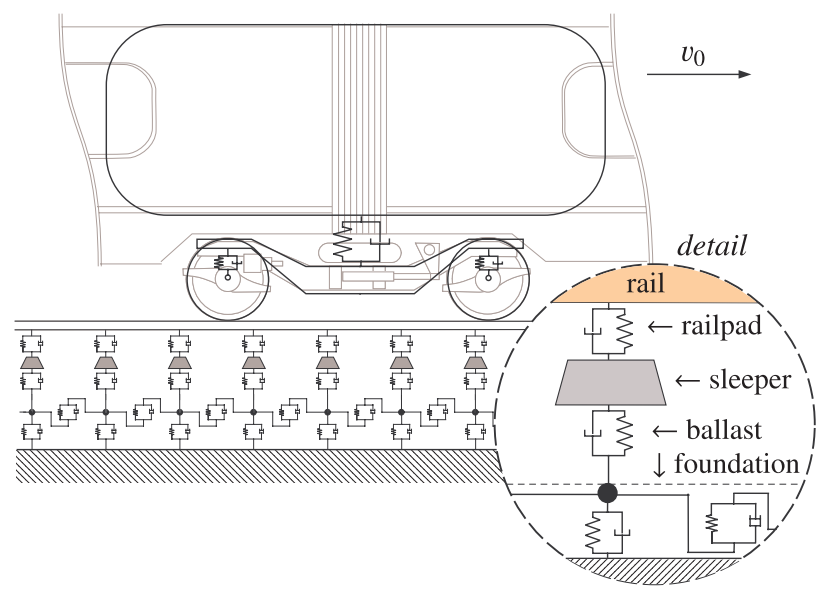

Figure 5. Vehicle/track/foundation simulation.

take into account the dynamic behaviour of the foundation, which plays an important role at low frequencies, a coupled lumped mass model (CLM) is added to the track model, with interconnection elements for the foundationto-foundation coupling [21]. 
The vehicle multibody system is, therefore, described by

$$
\left.\mathbf{M}\left(\underline{\mathbf{q}}_{v}\right) \cdot \underline{\ddot{\mathbf{q}}}_{v}+\underline{\mathbf{h}}_{(\mathbf{q}}, \underline{\dot{\mathbf{q}}}_{v}, t\right)=0
$$

where $\mathbf{M}$ is the mass matrix and $\underline{\mathbf{h}}$ represents a general term gathering among others the contribution of the applied forces. Vehicle degrees of freedom are defined by $n_{c p}$ configuration parameters included in the vector $\mathbf{q}_{v}$. Equations of motion of the track have the following form

$$
\mathbf{M}_{t} \underline{\ddot{\mathbf{q}}}_{t}+\mathbf{C}_{t} \underline{\dot{\mathbf{q}}}_{t}+\mathbf{K}_{t} \underline{\mathbf{q}}_{t}=\underline{\mathbf{f}}_{t}
$$

where the subscripts $t$ are related to the track (including the foundations). Track stiffness $\mathbf{K}_{t}$, damping $\mathbf{C}_{t}$ and mass $\mathbf{M}_{t}$ matrices are defined with the help of the dynamic parameters of the track in terms of mass, stiffness and damping. For vehicle/track coupling, the wheel/rail contact is defined by non-linear Hertz's contact stress law in force vector $\underline{\mathbf{f}}_{t}$, implying the non-linear relationship between the imposed load $N$ and the material deformation, including the rail defect

$$
N=K_{H z}\left(z_{w, i}-z_{r, i}-h_{\text {defect }}\right)^{3 / 2},
$$

where $z_{w, i}$ is the vertical position of the wheel $i$ and $z_{r, i}$ the corresponding vertical displacement at the rail. The coefficient $K_{\mathrm{Hz}}$ depends on the radii of curvature of the wheel and the rail profile, and the elasticity of the material of both bodies. The analytical expression $h_{\text {defect }}$ of the defect takes into account the vehicle wheel radius $R_{w}$. The wheel contact with the defect starts when the centre of the wheel $x$ is horizontally distant by

$$
l_{0}=\sqrt{\Delta h\left(2 R_{w}-\Delta h\right)} .
$$

At this moment, the wheel climbs by following the function depending on the rail coordinate $x$

$$
h_{\text {defect }}(x)=\sqrt{R_{w}^{2}-\left(x-x_{0}-l_{0}\right)^{2}}+\Delta h-R_{w}
$$

representing the rail defect, with $x_{0}$ the position of the wheel when it hits the defect and $l_{0}$ the distance between $x_{0}$ and the start of the defect. Of course, after wheel climbing $\left(x>x_{0}+l_{0}\right)$, the height is constant $h_{\text {defect }}(x)=$ $\Delta h$. The wheel fall is obtained symmetrically from the climbing. In addition to this local defect, an overall track irregularity is included, using analytical functions developed by the Association of American Railroads [9]. The rail unevenness is therefore included according to data collected by the railways operator. A C++ object-oriented program was developed, using the EasyDyn library [22]. An application based on either MuPad or Xcas platform generates symbolic kinematic expressions for the vehicle. The MuPad/Xcas platform creates a $\mathrm{C}++$ code directly compilable against the EasyDyn library. The definition of problem is completed by the applied forces (suspensions, wheel/rail contact) and a link to the track model (which is already established and depends on site parameters only). The generalized coordinates approach is used to obtain a system of pure ordinary differential equations, without constraint equations. An implicit scheme is used for the

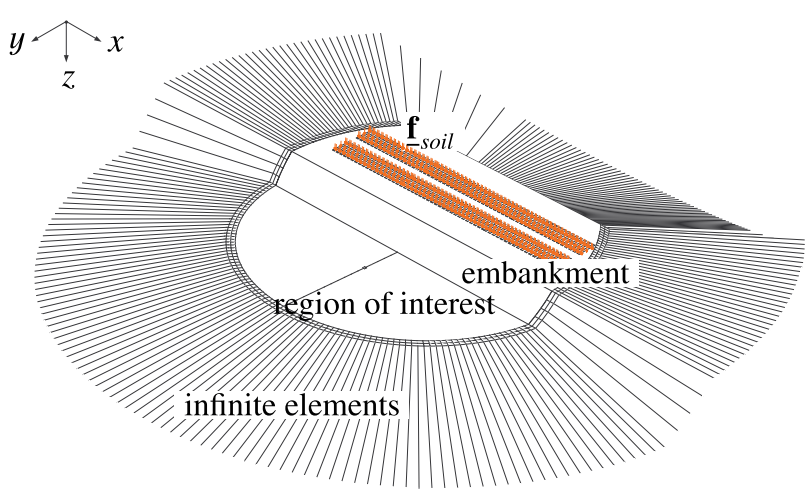

Figure 6. Finite element soil modelling using infinite elements and viscous boundary conditions.

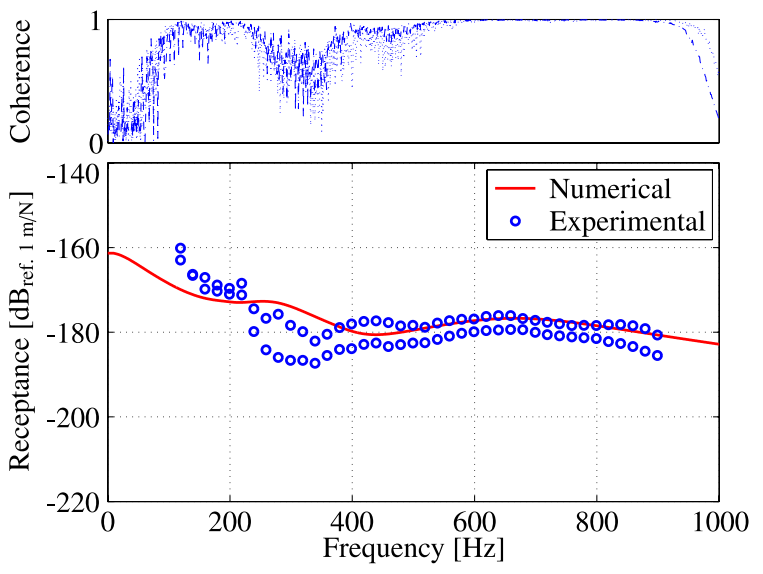

Figure 7. Numerical and experimental track receptance.

simulation in this first step. The ballast reactions are then saved and used as input forces $\underline{\mathbf{f}}_{\text {soil }}$ in second step.

This second step addresses the dynamics of the soil subsystem, with the soil surface forces representing contribution from the sleepers (Fig. 6). The dynamic ground response is calculated with a finite element method (under software package ABAQUS), best suited to three-dimensional analysis. Some analyses were recently conducted by the authors to improve the performance of their finite element model, namely:

- Complex geometry. A fully three-dimensional finite element model allows treating complex geometry (track embankment, inclined layer interfaces). Moreover, variability in track profile and high ground vibrations originating in singular rail surface defects can be treated without any difficulty.

- Non-reflecting boundary conditions. The combined use of viscous boundaries and infinite elements provides more efficient non-reflecting condition than classical setups (free or fixed boundaries). Here, the small dependence on incident wave angle and dynamic parameters is quantitatively carried out for each solution. A spherical soil border geometry is defined, to which infinite elements are attached. This convex shape configuration insures the condition of noncrossing infinite elements.

- Reasonable computation time. The simulation in time domain is an interesting solution to study 


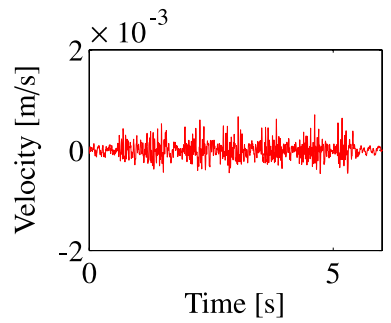

(a) $v_{z}^{E}(t)\left(x_{R}=13 \mathrm{~m}\right)$

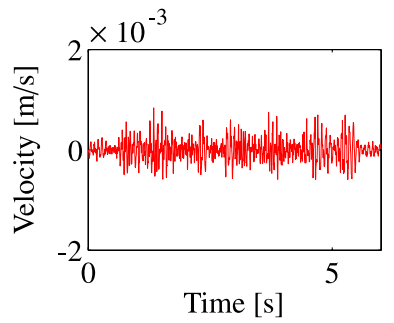

(e) $v_{y}^{E}(t)\left(x_{R}=14 \mathrm{~m}\right)$

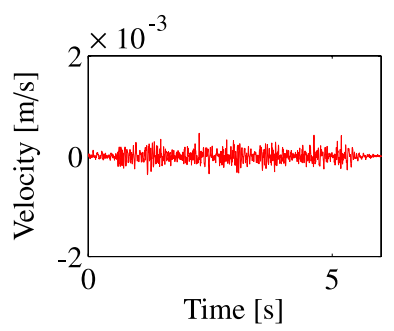

(i) $v_{z}^{E}(t)\left(x_{R}=16 \mathrm{~m}\right)$

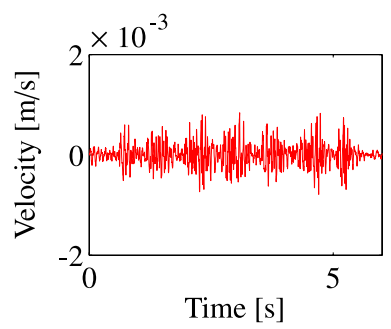

(m) $v_{x}^{E}(t)\left(x_{R}=20 \mathrm{~m}\right)$

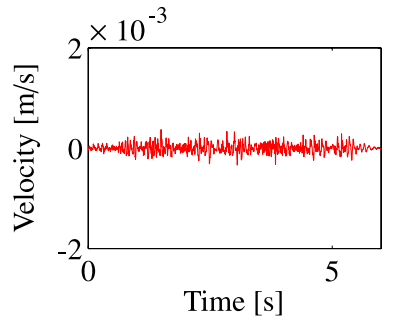

(q) $v_{z}^{E}(t)\left(x_{R}=20 \mathrm{~m}\right)$

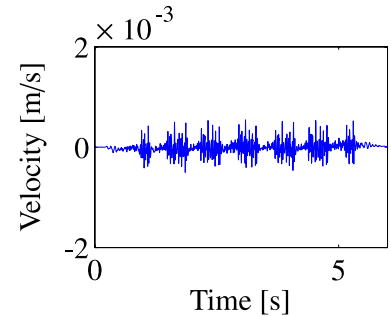

(b) $v_{z}^{N}(t)\left(x_{R}=13 \mathrm{~m}\right)$

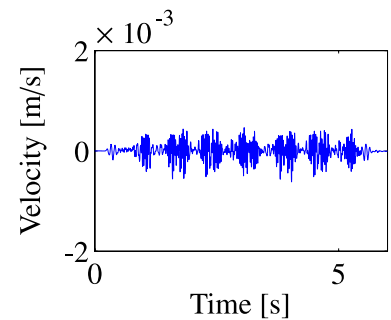

(f) $v_{y}^{N}(t)\left(x_{R}=14 \mathrm{~m}\right)$

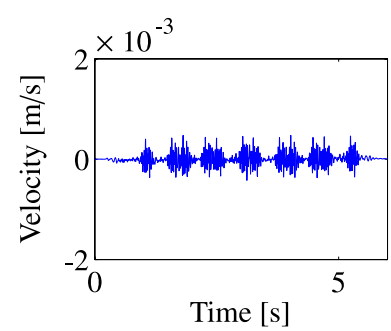

(j) $v_{z}^{N}(t)\left(x_{R}=16 \mathrm{~m}\right)$

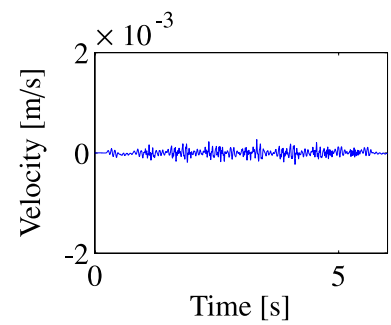

(n) $v_{x}^{N}(t)\left(x_{R}=20 \mathrm{~m}\right)$

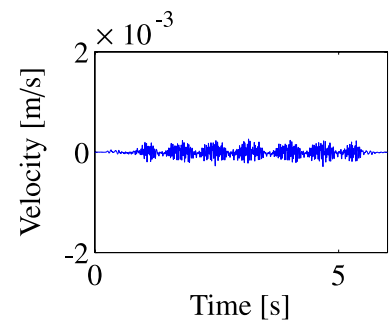

(r) $v_{z}^{N}(t)\left(x_{R}=20 \mathrm{~m}\right)$

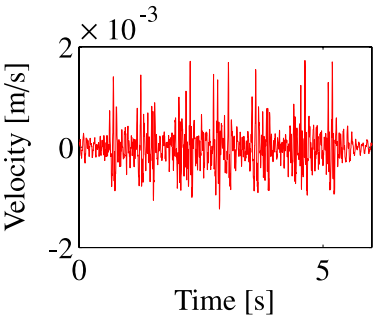

(c) $v_{x}^{E}(t)\left(x_{R}=14 \mathrm{~m}\right)$

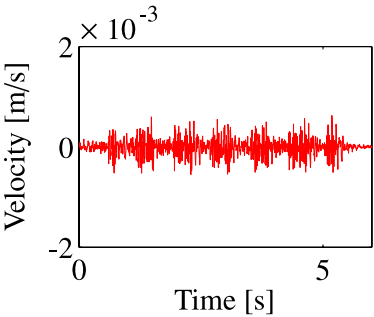

(g) $v_{z}^{E}(t)\left(x_{R}=14 \mathrm{~m}\right)$

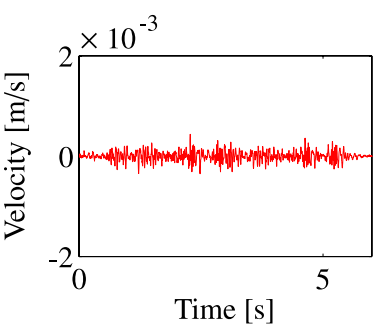

(k) $v_{z}^{E}(t)\left(x_{R}=18 \mathrm{~m}\right)$

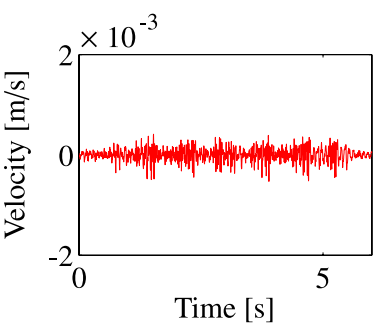

(o) $v_{y}^{E}(t)\left(x_{R}=20 \mathrm{~m}\right)$

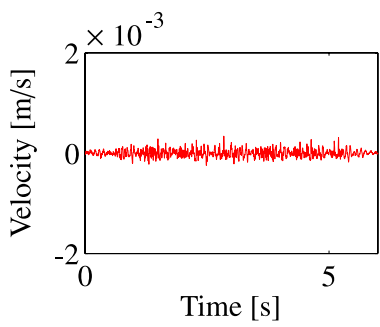

(s) $v_{z}^{E}(t)\left(x_{R}=22 \mathrm{~m}\right)$

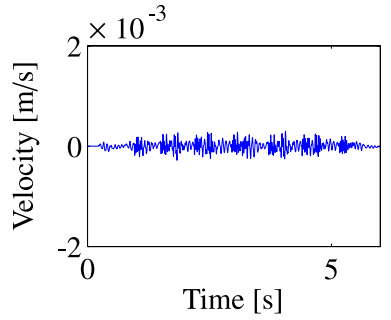

(d) $v_{x}^{N}(t)\left(x_{R}=14 \mathrm{~m}\right)$

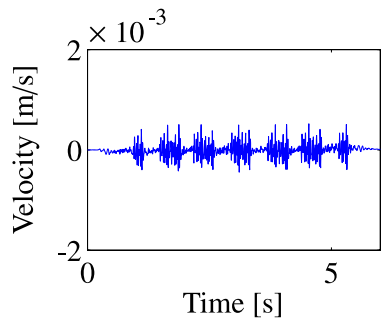

(h) $v_{z}^{N}(t)\left(x_{R}=14 \mathrm{~m}\right)$

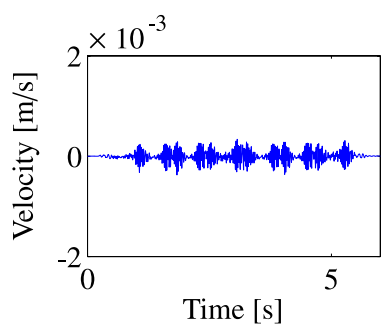

(1) $v_{z}^{N}(t)\left(x_{R}=18 \mathrm{~m}\right)$

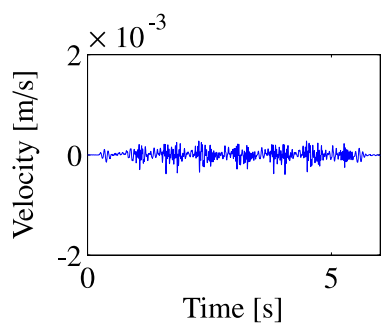

(p) $v_{y}^{N}(t)\left(x_{R}=20 \mathrm{~m}\right)$

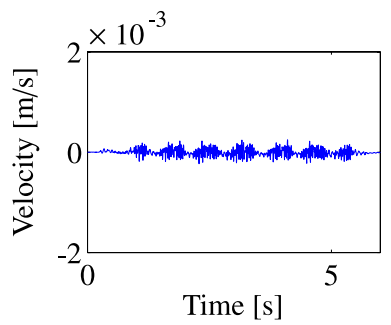

(t) $v_{z}^{N}(t)\left(x_{R}=22 \mathrm{~m}\right)$

Figure 8. Predicted and measured time history of vertical ground velocity at various distances from the track due to the passage of an AM96 unit $(2 \times 3$ carriages $)$ on track A at a speed of $125 \mathrm{~km} / \mathrm{h}$.

ground vibrations in a relatively small region of interest. As ground vibrations are inherently a transient phenomenon, the time domain analysis is appropriate to simulate wave propagation and does not impose any condition on the domain size, which would be required in the frequency domain. Moreover, the equations of motion describing the soil dynamics are integrated using explicit central difference integration to reduce the computational burden.

For the soil subsystem (second step), the governing equations of motion of the soil subsystem can be written

$$
\mathbf{M}_{s} \underline{\ddot{\mathbf{q}}}_{s}+\mathbf{C}_{s}+\mathbf{C}_{d} \underline{\dot{\mathbf{q}}}_{s}+\mathbf{K}_{s} \underline{\mathbf{q}}_{s}=\underline{\mathbf{f}}_{s o i l}
$$




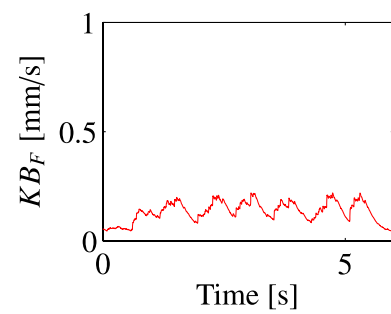

(a) $K B_{F, z}^{E}(t)\left(x_{R}=13 \mathrm{~m}\right)$

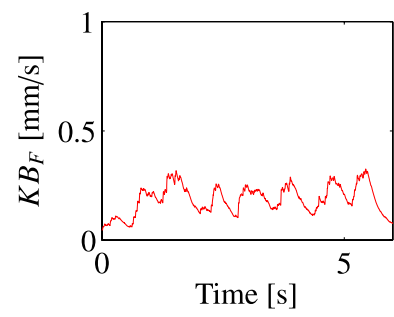

(e) $K B_{F, y}^{E}(t)\left(x_{R}=14 \mathrm{~m}\right)$

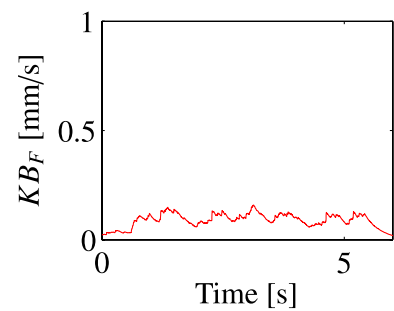

(i) $K B_{F, z}^{E}(t)\left(x_{R}=16 \mathrm{~m}\right)$

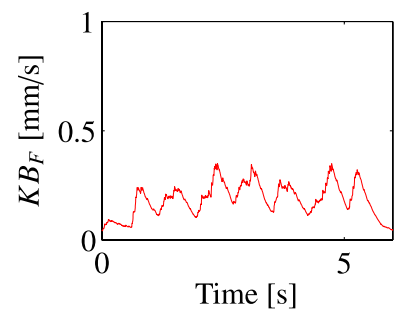

(m) $K B_{F, x}^{E}(t)\left(x_{R}=20 \mathrm{~m}\right)$

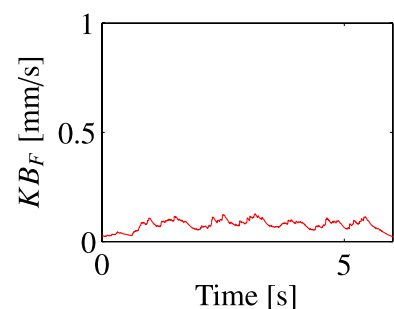

(q) $K B_{F, z}^{E}(t)\left(x_{R}=20 \mathrm{~m}\right)$

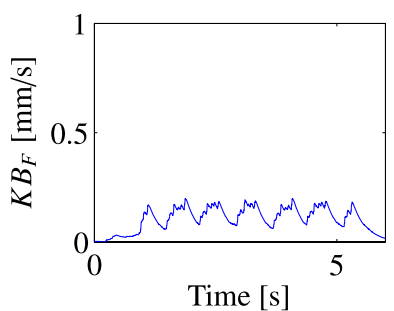

(b) $K B_{F, z}^{N}(t)\left(x_{R}=13 \mathrm{~m}\right)$

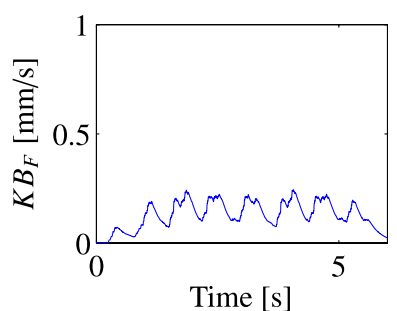

(f) $K B_{F, y}^{N}(t)\left(x_{R}=14 \mathrm{~m}\right)$

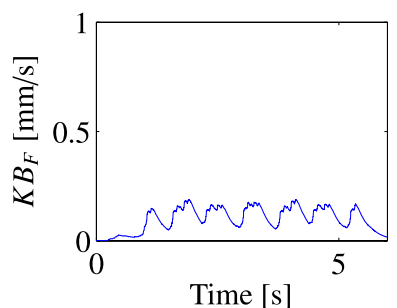

(j) $K B_{F, z}^{N}(t)\left(x_{R}=16 \mathrm{~m}\right)$

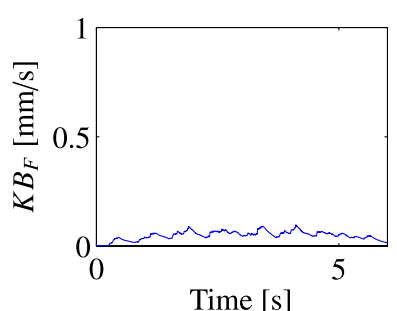

(n) $K B_{F, x}^{N}(t)\left(x_{R}=20 \mathrm{~m}\right)$

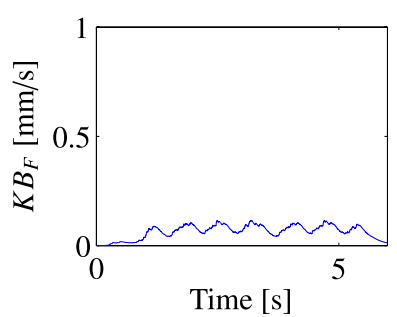

(r) $K B_{F, z}^{N}(t)\left(x_{R}=20 \mathrm{~m}\right)$

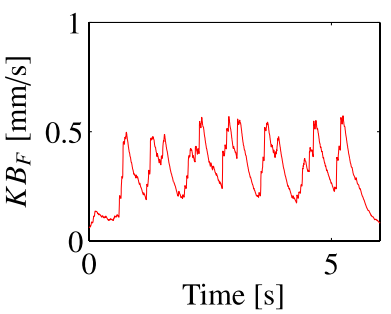

(c) $K B_{F, x}^{E}(t)\left(x_{R}=14 \mathrm{~m}\right)$

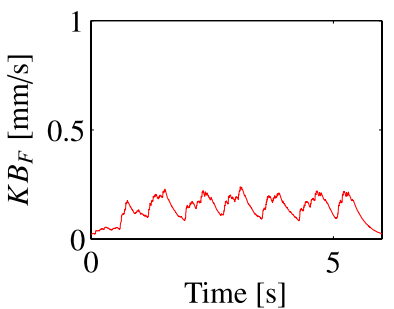

(g) $K B_{F, z}^{E}(t)\left(x_{R}=14 \mathrm{~m}\right)$

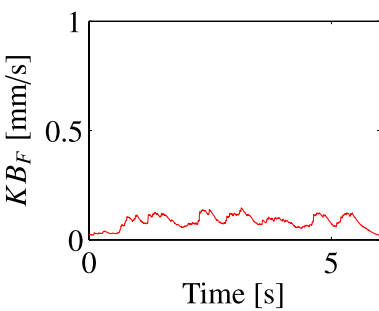

(k) $K B_{F, z}^{E}(t)\left(x_{R}=18 \mathrm{~m}\right)$

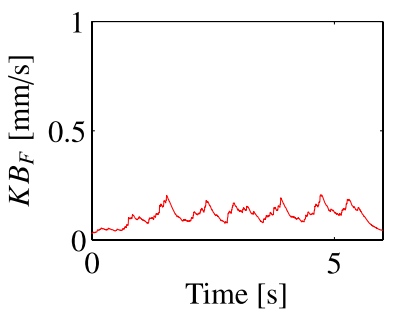

(o) $K B_{F, y}^{E}(t)\left(x_{R}=20 \mathrm{~m}\right)$

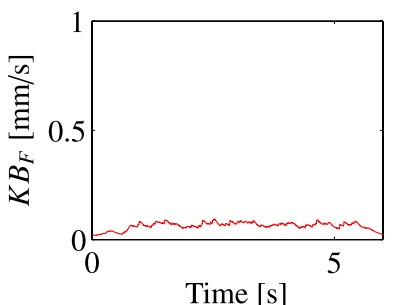

(s) $K B_{F, z}^{E}(t)\left(x_{R}=22 \mathrm{~m}\right)$

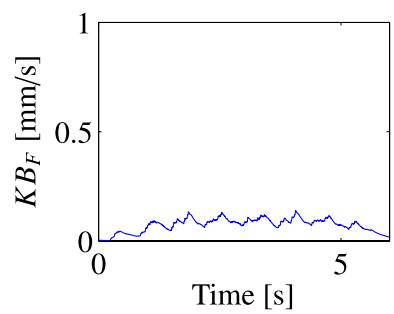

(d) $K B_{F, x}^{N}(t)\left(x_{R}=14 \mathrm{~m}\right)$

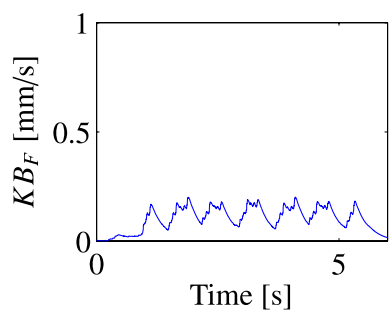

(h) $K B_{F, z}^{N}(t)\left(x_{R}=14 \mathrm{~m}\right)$

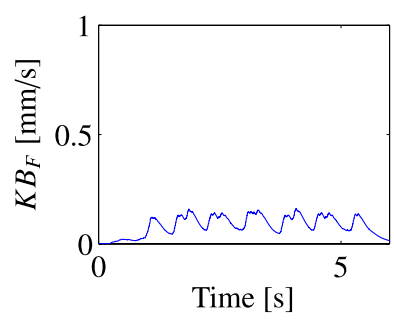

(l) $K B_{F, z}^{N}(t)\left(x_{R}=18 \mathrm{~m}\right)$

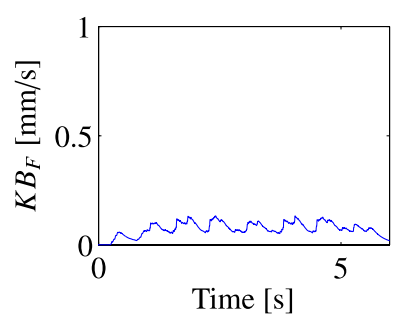

(p) $K B_{F, y}^{N}(t)\left(x_{R}=20 \mathrm{~m}\right)$

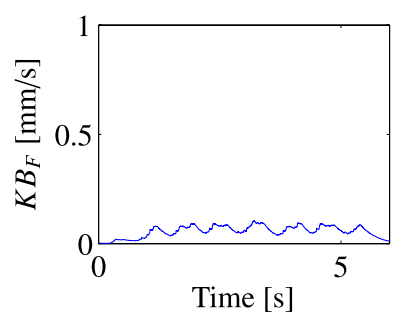

(t) $K B_{F, z}^{N}(t)\left(x_{R}=22 \mathrm{~m}\right)$

Figure 9. Predicted and measured weighted severity $K B_{F}(t)$ of vertical ground velocity at various distances from the track due to the passage of an AM96 unit $(2 \times 3$ carriages $)$ on track A at a speed of $125 \mathrm{~km} / \mathrm{h}$.

where $\underline{\mathbf{q}}_{s}$ is the vector related to the degrees of freedom of the soil subsystem. $\mathbf{K}_{s}$ and $\mathbf{M}_{s}$ are the soil mass and stiffness matrices, respectively, and $\mathbf{C}_{s}$ the intrinsic damping matrix, representing the soil viscous damping contribution, which is defined as

$$
\mathbf{C}_{s}=\beta \mathbf{K}_{s} \text {. }
$$

Viscous boundary, represented by a damping matrix $\mathbf{C}_{d}$ is added on the junction between finite and infinite elements, for preventing any residual reflected waves in the region of interest.

\section{Results and analysis}

\subsection{Track receptance validation}

A first validation is derived by comparing the numerical and experimental track receptances. The numerical 
receptances are calculated from a finite element model of the track, according to preceding description (rail - railpad - sleeper - ballast - CLM model), for any excitation point $j$ and any response point $i$

$$
H_{i j}(f)=\left[\left(\mathbf{K}_{t}+j 2 \pi f \mathbf{C}_{t}-(2 \pi f)^{2} \mathbf{M}_{t}\right)^{-1}\right]_{i j} .
$$

Once the numerical construction is performed, a comparison with vertical experimental receptance can be done. Figure 7 shows an example of results of rail receptance, obtained for the studied site, when the excitation is also on the rail. An overall agreement is obtained between $70 \mathrm{~Hz}$ and $900 \mathrm{~Hz}$ where the coherence is relatively of good quality. These results reveals that the CLM model well captures the track/soil interaction.

\subsection{Ground vibrations validation}

The desired outcome mainly deals with the interaction of the wheels with the singular defect. The dynamic simulation is performed considering a fully loaded vehicle, just as during experiment. The analysis of results and the comparison with the on-site measurements are presented on Figs. 8 and 9. The validation is based on the time history of experimental $v_{i}^{E}(t)$ and numerical $v_{i}^{N}(t)$ velocities along the three directions $(i=x, y$ and $z$ ), for various distances $x_{R}$ from the track, and the corresponding weighted vibration severities $\left(K B_{F, i}^{E}(t)\right.$ and $\left.K B_{F, i}^{N}(t)\right)$. The latter is described by the maximum of the time-averaged signal [23]:

$$
K B_{F_{i}}(t)=\sqrt{\frac{1}{\tau} \int_{0}^{t} K B_{i}^{2}(\xi) e^{-\frac{t-\xi}{\tau}} \mathrm{d} \xi}
$$

where the weighted velocity signal $K B_{i}(t)$ is obtained by passing the original velocity signal $v_{i}(t)$ through the highpass filter

$$
H_{K B}(f)=\frac{1}{\sqrt{1+(5.6 / f)^{2}}} .
$$

The assimilation time $\tau$ is typically equal to $0.125 \mathrm{~s}$, which takes into account transient phenomena, such as impacts or shocks, that would otherwise be masked if a simple rms operation was performed.

In the comparison of simulated and measured time histories (Fig. 8), a high agreement is observed for the vertical $(z)$ and lateral $(y)$ components. Both velocity trace histories have similarities in timing and magnitude, although the passing of each wheelset is more clearly defined for the numerical model. Regarding the longitudinal $(x)$ components, the model underestimates the vibration levels, the experimental results presenting highlevel vibrations, greater than along the vertical direction. This effect is less pronounced for the lateral direction. This high difference is possibly caused by the impact during the wheel/rail joint interaction which induces large dynamic forces along the longitudinal direction and that the model fails to account for, as it works exclusively in the vertical direction. This confirms that the horizontal components of vibration generated by the passing of train cannot be ignored in vibration intensity evaluation. The

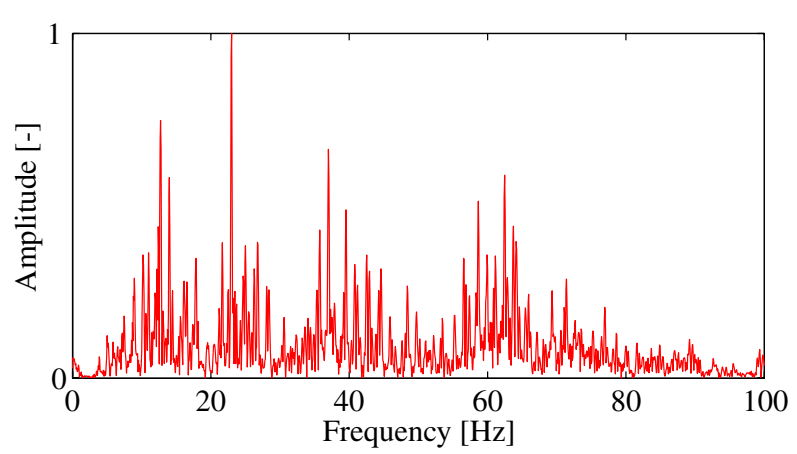

(a)

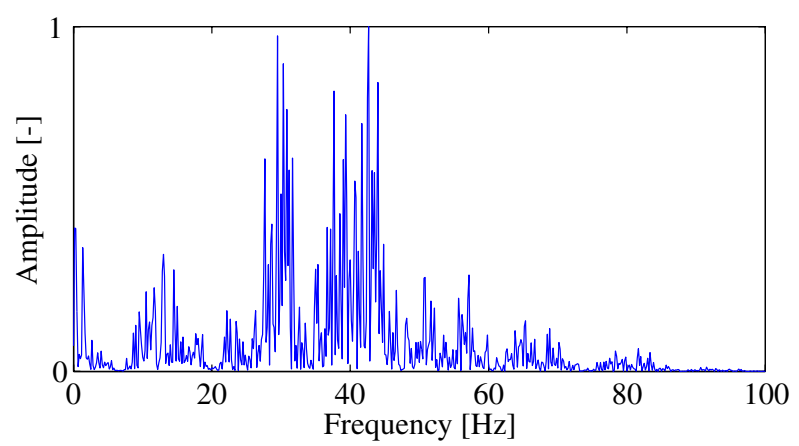

(b)

Figure 10. Experimental (a) and numerical (b) spectral contents of vertical ground velocity at $14 \mathrm{~m}$ from the track due to the passage of an AM96 unit $(2 \times 3$ carriages $)$ on track A at a speed of $125 \mathrm{~km} / \mathrm{h}$.

corresponding weighted vibration severities confirm these findings and better show the passing of each wheelset. The corresponding frequency contents for a distance $x_{R}=$ $14 \mathrm{~m}$ from the track are presented in Fig. 10. Although the frequency content is spread over a range up to $100 \mathrm{~Hz}$, the dominant frequencies are in the frequency range $0-50 \mathrm{~Hz}$. Once again, predicted spectra have a good correlation with the experimental data. Both data sets identify several dominant frequencies at $13 \mathrm{~Hz}, 29 \mathrm{~Hz}$, $37 \mathrm{~Hz}$, and $52 \mathrm{~Hz}$. This is due to the amplitude modulation caused by the successive axle load passages, and the soil resonance around $26 \mathrm{~Hz}$ [17]. Some differences between experimental and numerical data are also observed in the peak magnitudes. With this analysis, it is concluded that the aforementioned numerical model is capable of replicating the experimental data with sufficient accuracy, especially in the vertical direction. Further investigations should be done to analyse the discrepancies in horizontal directions.

\subsection{Interest of numerical results}

The effect of singular defects and vehicle speed can be investigated, as is presented in Fig. 11 for an AM96 unit running $(4 \times 3$ carriages $)$ on track $B$ at a speed of $115 \mathrm{~km} / \mathrm{h}$. The peak particle velocity $P P V$ is retained as primary indicator since it is dedicated to vibration effects on structures [24,25]. $P P V$ is defined as the maximum absolute amplitude of the velocity time signal

$$
P P V=\max \left|v_{z}\right| \text {. }
$$




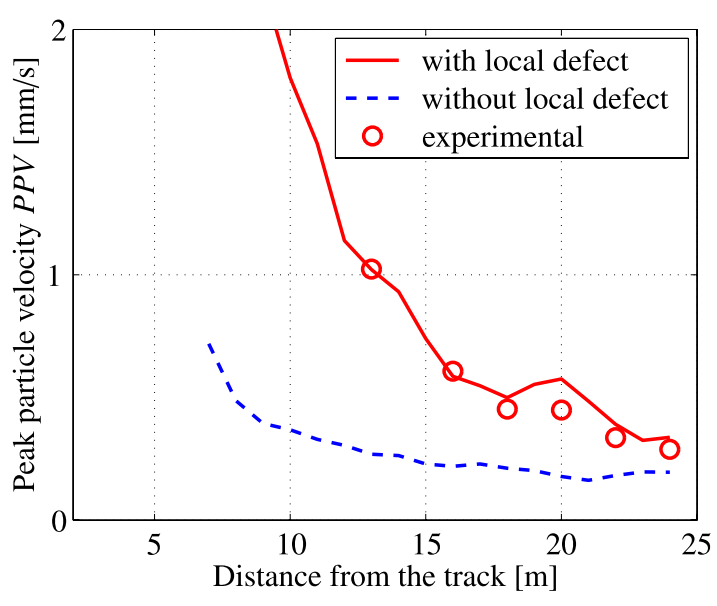

(a) Analysis of a singular defect $\left(v_{0}=115 \mathrm{~km} / \mathrm{h}\right.$ on track B)

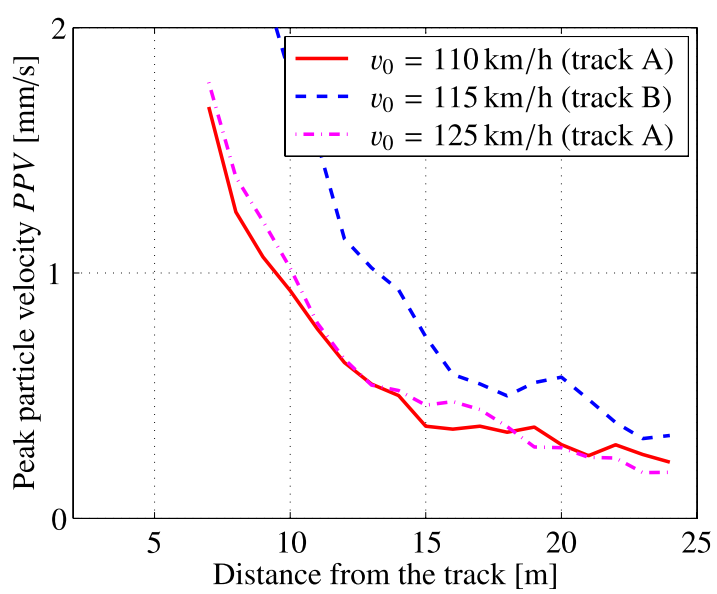

(b) Analysis of the vehicle speed and followed track

Figure 11. Comparison of predicted peak particle velocity as a function of the distance from the track.

In Fig. 11a, experimental data are included for an additional validation with respect to the distance. The level decrease obtained by suppressing the rail joint in the numerical model is quantified. The gain illustrated by Fig. 11a is substantial, especially for the near field (up to $80 \%$ compared to the reference case). A simple sensitivity calculation with the speed in a small range of interest is also performed (Fig. 11b). The contrast is not strong for a variation of $10 \%$ in speed, magnitudes are higher or lower depending on the distance from the track. The effect of the vehicle direction (track A or B) is also presented, showing the same tendency as the distance from the track.

\section{Conclusions}

This study provides a satisfactory analysis of physical problems related to railways-induced ground vibrations application where a singular defect presents on the rail surface and a complex geometry (track embankment) are taken into account. Vibration levels recorded in the free field next to the railway line are compared to their numerical counterparts, in order to validate the proposed model. Moreover, a sensitivity analysis can be conducted in order to globally verify factors affecting the generation and the propagation of vibrations induced by domestic trains. Results of the present contribution illustrate a substantial influence of the presence of a rail joint on ground vibrations generated by the passage of a AM96 unit.

The authors acknowledge the Belgian project management office TUC Rail for its support during the experimental campaign.

\section{References}

[1] J. Alias, La Voie Ferrée - Technique de Construction et d'Entretien, 2nd edn. (Eyrolles, Paris (France), 1984)

[2] C. Madshus, A.M. Kaynia, Journal of Sound and Vibration 231, 689 (2000)

[3] G. Degrande, L. Schillemans, Journal of Sound and Vibration 247, 131 (2001)

[4] J. Kogut, G. Lombaert, S. François, G. Degrande, W. Haegeman, L. Karl, High speed train induced vibrations: in situ measurements and numerical modelling, in 10th International Congress on Sound and Vibration (Stockholm (Sweden), 2003)

[5] P. Galvín, J. Domínguez, Soil Dynamics and Earthquake Engineering 29, 641 (2009)

[6] N. Triepaischajonsak, D.J. Thompson, C.J.C. Jones, J. Ryue, J.A. Priest, Journal of Rail and Rapid Transit 225, 140 (2011)

[7] D. Connolly, A. Giannopoulos, W. Fan, P.K. Woodward, M. Forde, Construction and Building Materials 44, 557 (2013)

[8] G. Kouroussis, O. Verlinden, C. Conti, Journal of Rail and Rapid Transit 226, 381 (2012)

[9] G. Kouroussis, D.P. Connolly, O. Verlinden, International Journal of Rail Transportation 2, 69 (2014)

[10] L. Auersch, S. Said, Earthquake Engineering and Engineering Vibration 9, 337 (2010)

[11] P.A. Costa, R. Calçada, A.S. Cardoso, Vibrations induced by railway traffic: influence of the mechanical properties of the train on the dynamic excitation mechanism, in 8th International Conference on Structural Dynamics: EURODYN 2011, edited by G.D. Roeck, G. Degrande, G. Lombaert, G. Müller (Leuven (Belgium), 2011), pp. 804-811

[12] G. Kouroussis, O. Verlinden, C. Conti, Vehicle System Dynamics 50, 619 (2012)

[13] D. Connolly, A. Giannopoulos, M. Forde, Soil Dynamics and Earthquake Engineering 46, 13 (2013)

[14] K. Vogiatzis, International Journal of Acoustics and Vibration 17, 59 (2012)

[15] K. Vogiatzis, Science of The Total Environment 439, $230(2012)$

[16] O. Laghrouche, D.L. Houédec, Soil-railway interaction for active isolation of traffic vibration, in Advances in Simulation and Interaction Techniques, edited by B.H.V. Topping (Civil-Comp Ltd, Edinburgh (Scotland), 1994), pp. 31-36 
[17] G. Kouroussis, C. Conti, O. Verlinden, Mechanics \& Industry 14, 99 (2013)

[18] G. Kouroussis, L. Van Parys, C. Conti, O. Verlinden, Advances in Engineering Software 70, 63 (2014)

[19] G. Kouroussis, O. Verlinden, Mechanical Sciences 4, 167 (2013)

[20] F.E. Richart, R.D. Woods, J.R. Hall, Vibrations of Soils and Foundations (Prentice-Hall, New Jersey (USA), 1970)

[21] G. Kouroussis, L. Van Parys, C. Conti, O. Verlinden, International Journal of Acoustics and Vibration 18, 163 (2013)
[22] O. Verlinden, L. Ben Fekih, G. Kouroussis, Theoretical \& Applied Mechanics Letters 3, 013012 (2013)

[23] Deutsches Institut für Normung, DIN 4150-2: Structural vibrations - Part 2: Human exposure to vibration in buildings (1999)

[24] Deutsches Institut für Normung, DIN 4150-3: Structural vibrations - Part 3: Effects of vibration on structures (1999)

[25] Association Suisse de Normalisation, SN-640312a: Les ébranlements - Effet des ébranlements sur les constructions (1992) 